\title{
Janire Castrillo Casado, Las mujeres vascas durante la Baja EDad Media, Madrid, Ed. SíleX, 2020, 398 PÁGS. ISBN: 978-84-7737-551-7.
}

\author{
$\mathrm{M}^{\mathrm{a}}$ IsABEL DEL VAL VALDiVIESO \\ Universidad de Valladolid
}

La presencia de las mujeres en las más diferentes actividades y espacios en los que se desarrolla la vida de la sociedad medieval puede rastrearse a través de la documentación de archivo y las fuentes en general, siempre que se hagan las preguntas pertinentes y se utilicen los métodos adecuados. Es cierto que las mujeres suelen aparecer en esas fuentes de una forma menos evidente que los varones, y también que su presencia es en muchas ocasiones subsidiaria a la de aquellos. Sin embargo, los datos que ofrecen son suficientes para estudiar ese tema, como ya ha puesto de manifiesto la historiografía especializada en la materia y como se desprende de la obra de Janire Castrillo Casado que ahora comentamos.

En la bibliografía disponible sobre la historia de las mujeres es fácil encontrar trabajos que se ocupan de las de la clase dominante (reinas, miembros de la familia real, nobles) y de las religiosas. Son menos frecuentes las investigaciones centradas en el resto de las mujeres, aquellas que no pertenecieron a ninguno de esos dos grupos. Más allá del sesgo historiográfico que privilegia el estudio de los círculos próximos al ejercicio del poder, las causas de esta situación hay que buscarlas en las dificultades que plantean las fuentes, mucho más directas y abundantes para los primeros sectores mencionados que para el último; y también en la perspectiva adoptada en ocasiones por los historiadores. Los estudios de caso, el análisis de un personaje concreto y su entorno, de una institución religiosa o de un grupo particular de mujeres vinculadas por lazos de parentesco o piedad, invitan a centrar la atención en determinado tipo de mujeres, dejando de lado a otras, precisamente a las del común.

De esta forma, las que no son miembros de casas reales, ni nobles, ni desarrollan su vida bajo el manto de lo eclesiástico o religioso, es decir, las que constituyen la inmensa mayoría de la población femenina, han gozado de menor atención. Son mujeres cuya vida se desarrolla en el campo o la ciudad, donde desempeñan múltiples funciones y todo tipo de tareas y trabajos dentro y fuera del hogar; se ocupan de muy diferentes y fundamentales aspectos del cotidiano vivir, contribuyendo con todo ello al desarrollo familiar, vecinal y social, además de al suyo propio. Precisamente una de las virtudes del libro de Janire Castrillo es que la mayor parte de sus protagonistas se encuadran en 
el común, aunque también se ocupa de las religiosas y de las señoras, ofreciendo así una visión de conjunto de las mujeres vascas del bajo medievo.

Abordar con profundidad su estudio exige elegir una muestra suficientemente amplia y delimitar el espacio a estudiar, además de definir el marco temporal. Ese es precisamente el punto de arranque del trabajo de la doctora Castrillo, que centra su investigación en los distintos territorios que hoy constituyen el País Vasco, en los que analiza la historia de las mujeres a lo largo del siglo XV y primeros años del XVI. En ese marco espaciotemporal, partiendo de un exhaustivo rastreo de las fuentes escritas disponibles, la autora ha logrado presentar un completo panorama de lo que debió de ser su existencia, regulada por las normas y costumbres que marcaron su cotidiano vivir, en un momento especialmente relevante, pues se trata de la centuria anterior a ese cambio radical que para ellas supuso el concilio de Trento.

El planteamiento de la obra es ambicioso, pero bien reflexionado y estructurado, de manera que ofrece una nueva visión de la sociedad vasca del momento a través del prisma de sus integrantes femeninas. Tras un breve pero expresivo prólogo del profesor Iñaki Bazán, la obra se estructura en torno a cuatro grandes temas que organizan y limitan la vida y acción de las mujeres: la familia; las disposiciones normativas; la conceptualización de la mujer y su reflejo en la práctica; y el mundo laboral.

Atendiendo a esos asuntos, van pasando por las páginas del libro personajes de condición diferente, desde las integradas en los sectores más destacados de la sociedad del momento hasta pobres, perseguidas y marginadas. La investigación realizada pone de manifiesto que en todos los casos se trata de personas a las que el poder patriarcal dominante define de forma similar, exigiendo comportamientos, en general, recatados y devotos, cuando no sumisos; y a las que impone unas normas comunes que limitan su capacidad en la toma de decisiones y en actuaciones ante la justicia. Pero también mujeres que son titulares bienes de los que solo ellas pueden disponer, y que saben defender sus derechos en la vida cotidiana, y ante la justicia cuando es preciso.

La imagen que nos transmite la obra de Castrillo Casado es la de una sociedad en la que las mujeres constituyen un pilar central de la organización social. Si mientras son menores y solteras están bajo la autoridad y control del padre o del grupo parental, una vez casadas su condición se transforma. Si bien ahora es el marido quien se alza sobre ellas, adquieren una situación en la que pueden ser propietarias y titulares de bienes de los que solo ellas pueden disponer, aunque hayan de hacerlo con la autorización marital, como es común en la época. En este como en los restantes capítulos, la autora avala sus afirmaciones con ejemplos procedentes de las fuentes, a través de los cuales vemos en qué situación se encontraban las mujeres en el seno familiar, cuáles eran sus capacidades y posibilidades de actuación en el mundo en el que viven, y cómo todo esto cambia si llegan a enviudar, ya que tras el fallecimiento del marido gozaban de una situación de mayor independencia y capacidad de acción.

Las mujeres bajomedievales, también en el País Vasco, fueron excluidas de buena parte de los quehaceres propios del ámbito del poder público, lo que las posiciona en 
inferioridad respecto a los varones. Como explica Janire Castrillo, esto quedaría en parte compensado por su posición en el contexto de la familia, donde se refuerza el papel de casadas y viudas. Como se observa en los fueros, rige el régimen castellano, pero con matices que se recogen en esas normas forales. De nuevo aquí los datos que proporciona la documentación escrita enriquecen la exposición, en la que se demuestra, por ejemplo, que pueden ser tutoras de sus hijos y albaceas y apoderadas de sus maridos; que participan en algunas acciones políticas colectivas; y que, en el caso de las señoras, estando solas, actúan igual que los varones, incluso en asuntos relacionados con los conflictos, como la recluta de tropas, la intervención en acuerdos y las tareas de mediación, actividades en las que también se ve en ocasiones a las que están al frente de comunidades religiosas. Por otro lado, es de destacar que el fuero reformado de las Encartaciones reconoce en algunos casos su intervención como árbitras.

La idea que esa sociedad tenía de las mujeres quedó en buena parte reflejada en la conocida Querella de las mujeres, de la que no son ajenos los territorios del País Vasco. Así se desprende de que el primer libro escrito en euskera que se conoce (cuyo autor fue Bernat de Etxepare) incluya un poema titulado "en favor de las mujeres", circunstancia que la autora recoge con acierto para avalar su hipótesis. En la vida real y cotidiana, así como en el ámbito de la especulación intelectual, las ideas del patriarcado dominante llevaron a primar en las mujeres la virginidad, castidad, fidelidad y silencio; según las fuentes manejadas por Castrillo, esta última cualidad llevó a intentar silenciarlas, y a reprimir a las endecheras. Quienes aceptaban más o menos ese patrón de comportamiento eran las "buenas mujeres", pero no todas cabían bajo tal denominación. La otra cara de la moneda viene representada por las que en la época se denomina a veces "malas mujeres", entre las que se encuentran las hechiceras y sorguiñas así como aquellas que no usan de su cuerpo conforme a la norma imperante, es decir las que realizaban prácticas sexuales cuyo fin no era la procreación en el seno del legítimo matrimonio.

Por último, la obra se orienta hacia el trabajo desarrollado por las mujeres en los territorios vascos durante la baja Edad Media. En este caso, la documentación permite recorrer los sectores en los que estuvieron presentes: el campo, el artesanado, la pesca y el comercio. Se constata que, como en otros lugares, se encuentran en casi todo tipo de ocupaciones, aunque no fueron integradas en las corporaciones de oficio. En esas agrupaciones estuvieron relegadas a actividades relacionadas con la fraternidad y ayuda mutua, si bien se ha podido documentar que, de forma excepcional, algunas tuvieron un papel más activo, debido a la ausencia o muerte de su marido. La autora destaca también la participación femenina en el gran comercio y el armado y flete de barcos.

El libro se cierra con un interesante apéndice documental y un listado de fuentes y bibliografía temáticamente organizado, que permiten a toda persona interesada en el tema acercarse a las fuentes directas de información y ampliar su conocimiento, si ese es su deseo. Previamente ofrece un capítulo de conclusiones en el que se exponen con claridad las líneas maestras de la investigación realizada y los resultados más sobresalientes, siempre avalados por los datos obtenidos de la amplia documentación manejada. De esta forma culmina esta obra que ofrece una clara y bien argumentada historia de las 
mujeres vascas del final del medievo, aunque podría decirse que, más allá de esto, lo que Janire Castrillo Casado ha conseguido es ofrecernos una panorámica de la sociedad vasca de ese momento, en la que las mujeres aparecen como auténticas protagonistas, y en la que se perciben con claridad las luces y sombras propias de aquella época y organización social. En definitiva, un libro que nos permite avanzar y profundizar en el conocimiento de la Historia. 